\title{
Implementasi Investasi dan Strategi Daya Saing Hijau Terhadap Green Banking di Kota Surakarta
}

\author{
I Gusti Putu Diva Awatara ${ }^{*}$ dan Anwar Hamdani ${ }^{1}$
}

${ }^{1}$ Program Studi Magister Manajemen STIE Adi Unggul Bhirawa, Jalan Mr. Sartono No.46 Surakarta, Indonesia 57135

*Penulis korespondensi, e-mail: igustiputudivaawatara@gmail.com

\begin{abstract}
Abstrak
Penerapan prinsip perbankan hijau tercermin dalam serangkaian inisiatif untuk program kemasyarakatan, pengembangan masyarakat dan program bisnis, dan mendorong investasi dalam bisnis yang lebih bertanggung jawab sebagai bentuk kepedulian tinggi Bank terhadap lingkungan. Penelitian ini bertujuan untuk menganalisis investasi hijau dan strategi daya saing hijau yang berdampak pada penerapan perbankan hijau di Kota Surakarta. Penelitian ini dilakukan dengan metode survei terhadap nasabah - nasabah Bank di Kota Surakarta. Sampel dalam penelitian ini adalah 75 responden. Metode pengumpulan data yang digunakan dalam penelitian ini adalah kuesioner dan observasi. Teknik analisis yang digunakan meliputi tes instrumen penelitian, yaitu uji validitas dan uji reliabilitas; Uji asumsi klasik meliputi: uji heteroskedastisitas, uji autokorelasi, uji normalitas, dan uji multikolinieritas. Pengujian hipotesis dilakukan dengan menggunakan analisis regresi linier berganda, uji t, uji F dan analisis koefisien determinasi $\left(\mathrm{R}^{2}\right)$. Hasil penelitian ini menunjukkan bahwa investasi hijau dan strategi persaingan hijau memiliki dampak pada penerapan perbankan Hijau di Kota Surakarta. Variabel yang memiliki dampak terbesar adalah strategi kompetitif hijau.
\end{abstract}

Kata kunci: investasi hijau, strategi persaingan hijau, perbankan hijau

\begin{abstract}
The implementation of green banking principle is reflected in a series of initiatives for the community program, community development and business programs, and encourages investment in more responsible businesses as a form of Bank's high concern for the environment. This study aims to analyze Green Investment, and Green Competitive Strategies that have an impact on the implementation of Green Banking in Surakarta City. This research was a survey conducted on bank customer in Surakarta City. The sample in this study was 75 respondents. Data collection methods use in this study were questionnaire and observation. The analysis technique used includes the test of the research instrument, namely the validity and reliability test; classic assumption test include: heteroscedasticity, autocorrelation, normality and multicollinearity test. Hypothesis test is done by using multiple linear regression analysis, $t$ test, F test and analysis of the coefficient of determination $\left(R^{2}\right)$. The results of this study indicate that green investment and green competitive strategies have an impact on the implementation of green banking in Surakarta City. The variable that has the greatest impact is Green Competitive Strategies.
\end{abstract}

Keywords: green investment, green competitive strategies, green banking 


\section{Pendahuluan}

Masalah paling rumit yang dihadapi dunia saat ini adalah perubahan iklim. Telah ada upaya secara terus menerus di seluruh dunia untuk mengukur dan mengurangi risiko climate change karena kegiatan manusia. Banyak negara, telah membuat komitmen yang diperlukan untuk melakukannya (Shruti, 2015). Bank sebagai bagian dari warga korporasi yang merupakan bagian dari warga korporasi dunia dan lingkungan sekitar, sepenuhnya mendukung kegiatan yang memberikan manfaat lebih dengan memprioritaskan ramah lingkungan dan ramah bagi iklim (green economy) yang dicanangkan pemerintah, dalam hal ini Kementerian Lingkungan Hidup dan Kehutanan (KLHK), Bank Indonesia (BI) serta Otoritas Jasa Keuangan (OJK). Upaya tersebut sejalan dengan dan merupakan bentuk kepatuhan Bank terhadap UU No. 32 tahun 2009 tentang Perlindungan dan Pengelolaan Lingkungan Hidup, yang mewajibkan semua kegiatan bisnis agar patuh terhadap UU ini dalam rangka menciptakan kelestarian lingkungan di masa yang akan datang dan sustainable.

Bank memahami bahwa ketidakpedulian terkait ketentuan ini akan meningkatkan risiko kredit, hukum dan reputasi untuk aspek keuangan dan perbankan. Bank dapat meningkatkan dan kepedulian ekstra terkait manajemen risiko lingkungan hidup, melalui serangkaian inisiatif pelestarian lingkungan dan penerapan prinsip ramah lingkungan baik dalam aktivitas operasional maupun penyaluran kredit Bank (green banking). Dalam praktiknya, green banking sebagai konsep yang mengharuskan lembaga keuangan untuk selalu memprioritaskan keberlanjutan lingkungan dalam menjalankan usahanya, memberikan sumbangan perbankan dalam mengoptimalkan pemerintah untuk meningkatkan posisi Indonesia sebagai paru-paru dunia agar menurunkan emisi gas rumah kaca. Penerapan prinsip green banking Bank tercermin dalam serangkaian inisiatif program kemasyarakatan, Bina Lingkungan dan Program Bisnis (PKBL), serta mensupport investasi dalam bisnis yang ramah lingkungan sebagai bentuk kepedulian bank terhadap lingkungan. Pada era revolusi 4.o dalam kondisi dinamis, pertumbuhan ekonomi di tingkat nasional, industri dan skala menengah kecil harus terus mengutamakan pertumbuhan yang ramah lingkungan agar tercapai pertumbuhan kinerja yang berkelanjutan. Bank menyadari bahwa kegiatan usaha perusahaan butuh sumber daya yang baik. Untuk itu, Bank diwajibkan menurunkan pengaruh negatif dari penggunaan keduanya, dan segera meminimalisir footprint ekologi Bank.

Konsep green banking bertujuan agar kelestarian alam dan lingkungan yang menjadi tempat hidup serta hajat hidup orang banyak bisa terjaga. Pelaksanaan Surat Edaran Bank Indonesia No. 21/9/UKU tanggal 25 Maret 1989 perihal "Kredit Investasi dan Penyertaan Modal" dimana pengucuran kredit harus memperhatikan AMDAL, selanjutnya UU nomor 10 tahun 1998 tentang perubahan atas UU nomor 7 Tahun 1992 tentang perbankan (1 persen membahas tentang minimalisasi risiko lingkungan; prinsip syariah) serta Peraturan Bank Indonesia No. 7/2/PBI/2005, mengenai kewajiban untuk melakukan appraisal. Kebijakan perkreditan yang berwawasan lingkungan sebaiknya tidak terbatas hanya pada menerapkan AMDAL dalam penilaian pemberian kredit saja. Kebijakan itu dilakukan oleh bank sampai kepada pembuatan perjanjian kreditnya, artinya, di antara klausul-klausul dalam perjanjian kredit hendaknya terdapat juga klausul-klausul yang dapat berperan sebagai pengendali agar nasabah debitor benar menggunakan kredit untuk membangun sarana pencegahan perusakan terkait pembangunan proyek yang di biayai dengan kredit tersebut. Penelitian ini bertujuan untuk menganalisis Green Investment, dan Green Competitive Strategies berdampak terhadap implementasi Green Banking di Kota Surakarta.

Menurut Heim \& Zenklusen (2005) faktor yang mempengaruhi bank dalam menerapkan green banking adalah kepuasan nasabah, kepedulian environment, corporate social responsibility tekanan masyarakat dan kebijakan goverment. Menurut Jun \& Cai (2001) keberhasilan green banking ditentukan kepuasan nasabah yang diidentifikasi dengan respon (kognitif atau afektif) yang berkaitan dengan fokus tertentu (yaitu pengalaman menggunakan produk yang terkait) dan terjadi pada waktu tertentu. Penelitian Tonmoy (2013) menjelaskan bahwa Green Competitive Strategies yang ditawarkan oleh industri perbankan dapat memberikan dampak positif kepada implementasi green banking sehingga dapat meningkatkan perilaku aktivitas perbankan yang ramah lingkungan. Hal ini dapat meningkatkan 
aktivitas industri perbankan untuk melaksanakan green banking karena jika Green Competitive Strategies berjalan dengan baik maka green banking dapat terlaksana dengan lancar (Naser, 2016).

\section{Metodologi Penelitian}

Penelitian ini termasuk penelitian survey yang dilakukan pada nasabah Bank di Solo. Populasi penelitian ini yaitu pegawai dan nasabah bank di Kota Surakarta. Metode sampel digunakan peneliti yaitu pengambilan sampel dengan tujuan karena responden yang dijadikan sampel adalah nasabah yang menerima pelayanan perbankan dengan menggunakan prinsip perbankan, sehingga jumlah sampel dalam penelitian ini berjumlah 75 nasabah. Pengumpulan data menggunakan kuesioner dan observasi. Asumsi klasik meliputi uji heteroskedastisitas, autokorelasi, normalitas dan multikolinieritas. Pengujian hipotesis yaitu analisis regresi linier berganda, uji t, uji F dan koefisien determinasi.

\section{Hasil dan Diskusi}

Uji instrumen dilakukan menggunakan program SPSS versi 15 . Uji ini dimaksudkan untuk mendeteksi kelayakan alat pengumpul data, yang berupa angket. Berdasarkan hasil uji validitas menunjukkan bahwa variabel green banking, green investment dan green competitive strategies seluruh item pernyataan dalam kondisi valid. Hasil uji reliabilitas menunjukkan bahwa Green Banking, Green Investment dan Green Competitive Strategies dalam kondisi reliabel. Hasil asumsi klasik memperlihatkan bahwa model penelitian ini tidak terjadi gangguan heteroskedastisitas, autokorelasi, normalitas dan multikolinieritas. Hasil analisis regresi linier berganda menunjukkan bahwa hasil analisis regresi signifikan (Tabel 1).

Tabel 1. Hasil Analisis Regresi

\begin{tabular}{|c|c|c|c|c|}
\hline Variabel & Beta & t Hit & Sig & Kesimpulan \\
\hline Contant & 1.033 & 0.703 & 0.484 & \\
\hline $\mathrm{X}_{1}$ & 0.098 & 4.176 & 0.000 & Ho. Ditolak/Signifikan \\
\hline $\mathrm{X}_{2}$ & 0.375 & 3.666 & 0.000 & Ho ditolak/Signifikan \\
\hline
\end{tabular}

Sumber: Analisis data primer, 2018

Tabel 1 memperlihatkan bahwa variabel Green Investment memiliki nilai signifikansi sebesar o,ooo $<\alpha=0,05$ maka Green Investment berpengaruh terhadap Green Banking. Variabel Green Competitive Strategies memiliki nilai sebesar o,ooo $<\alpha=0,05$ maka Green Competitive Strategies berpengaruh terhadap Green Banking. Nilai Koefisien determinasi $\left(\mathrm{R}^{2}\right)$ memperlihatkan nilai $\mathrm{R}^{2}$ adalah o,757 artinya $75,7 \%$ variabel bebas dapat menjelaskan variasi variabel terikat, sisanya $24,3 \%$ dijelaskan oleh variabel lain, sehingga penggunaan variabel bebas dalam menjelaskan variasi variabel terikat sesuai.

Berdasarkan hasil penelitian di atas, kedua variabel independent mempunyai pengaruh positif terhadap Green Banking. Kedua variable tersebut adalah Green Investment dan Green Competitive Strategies. Hasil penelitian di atas dapat digunakan sebagai media pembuktian atas hipotesis yang menyatakan, "terdapat dampak Green Investment dan Green Competitive Strategies terhadap implementasi Green Banking di Kota Surakarta”. Secara parsial, juga kedua variabel juga berdampak pada implementasi Green Banking di Kota Surakarta. Hal ini sejalan dengan teori yang dikemukakan oleh Naser, 2016) Prinsip dasar green invesment adalah memaksimalkan bank agar mengoptimalkan membiayai aktivitas ramah lingkungan seperti energi ramah lingkungan, efisiensi energi, organic culture, eco-tourism, transportasi ramah lingkungan, dan produk label ramah lingkungan. Upaya tersebut wujud awareness bank terhadap resiko terjadi masalah lingkungan pada kegiatan yang dibiayai sehingga dapat menimbulkan dampak negatif berupa penurunan kualitas kredit dan reputasi bank (IFC, 2016).

Green Banking adalah segala bentuk jenis mekanisme perbankan dimana akan diperoleh manfaat lingkungan. Sebuah bank konvensional yang menjalankan Green Banking dengan mengarahkan operasi intinya menuju perbaikan lingkungan. Green Banking merupakan strategi perbankan inklusif yang akan memastikan pembangunan ekonomi yang substansial dan mempromosikan praktik ramah lingkungan 
(Raab, 2015). Green Banking adalah kegiatan operasional di sektor keuangan dengan fokus khusus pada faktor lingkungan, ekologi dan sosial, menargetkan konservasi alam dan sumber daya alam. Istilah ini secara luas mencakup penciptaan kesadaran dan promosi proyek dan praktik ramah lingkungan, dan pengurangan bahan karbon secara keseluruhan ( $\mathrm{Tu}, 2017)$. Melalui green banking, suatu lembaga keuangan tidak hanya diminta untuk meningkatkan standar mereka sendiri, tetapi juga memainkan peran aktif dalam promosi proyek dan praktik ramah lingkungan melalui dana pembiayaan yang diberikan oleh bank. Pembiayaan green banking lebih dari pembiayaan investasi biasa, investasi ini terdiri dari unsur-unsur seperti rancangan sistem keuangan yang ramah lingkungan dan ramah iklim secara keseluruhan dan pengelolaan risiko lingkungan dan iklim di lembaga keuangan (Karl, 2017). Green Banking adalah organisasi perbankan yang prioritas sustainable praktek bisnisnya. Kondisi ini berbasiskan 4 aspek yakni alam, well-being, ekonomi dan masyarakat (Chen, 2010).

Bank hijau sebagai dorongan perbankan untuk mengutamakan pemenuhan keberlanjutan dalam penyaluran kredit atau kegiatan operasionalnya (Suresh, 2015). Bank memiliki hak penuh meminimalisir cost atau tidak, tergantung kegiatan yang akan dibiayai dengan pinjaman bank berpengaruh terhadap environment (Goyal, 2011). Chen (2010) menyatakan bahwa perbankan yang menerapkan green banking bertujuan agar mampu memenuhi keinginan masyarakat agar lebih peduli pada masalah lingkungan, meningkatkan daya saing, memperbaiki citra perusahaan, membuka kesempatan pasar baru dan meningkatkan nilai produk. Beberapa manfaat lain dari green banking adalah meminimalisir penggunaan kertas dalam melakukan transaksi perbankan untuk dialihkan melalui teknologi bank, sms banking, phone banking dan ATM banking sehingga masyarakat akan terbiasa berperilaku bertransaksi di bank berbasis teknologi.

Semakin tinggi kebutuhan energi dalam mengoptimalkan pembangunan, kegiatan keuangan berkelanjutan, sehingga meningkatkan pasokan sumberdaya cukup tinggi. Dukungan kepada sektor sumberdaya diikuti dukungan developing sektor ekonomi prioritas yaitu sektor yang memiliki multiplier effect tinggi seperti pertanian dalam arti luas, industri pengolahan, infrastruktur, UMKM serta energi (Gobinda, 2015). Sektor perbankan dapat berperan sebagai mediasi antara pembangunan ekonomi dan pencegahan kerusakan lingkungan untuk pengembangan keberlanjutan lingkungan dan investasi sosial. Green banking diharapkan dapat membantu mengurangi emisi karbon (Benedikter, 2011). Menurut Jones (2001) faktor yang mempengaruhi green banking adalah kemampuan nasabah untuk mendapatkan informasi dan layanan dari website, sesuai format isi, pengaturan perangkat keras dan lunak yang digunakan. Aksesibilitas diartikan sebagai kemampuan nasabah untuk mengakses mata kuliah.

Green banking memiliki hubungan dengan green invesment, dapat dilihat pengaruhnya pada sikap terhadap investasi. Penerapan strategi posisi hijau dapat meningkatkan persepsi merek, indikasi hubungan positif antara green marketing dan green image. Menurut Heim \& Zenklusen (2005) faktor yang mempengaruhi bank dalam menerapkan green banking adalah kepuasan nasabah, kepedulian lingkungan, tanggung jawab sosial perusahaan tekanan masyarakat dan kebijakan pemerintah. Menurut Jun \& Cai (2001) keberhasilan green banking ditentukan kepuasan nasabah yang sesuai dengan respon berkaitan dengan tujuan dan terjadi pada waktu tertentu.

Temuan dampak Green Competitive Strategies terhadap pelaksanaan Green banking sejalan dengan penelitian Tonmoy (2013) menjelaskan bahwa Green Competitive Strategies yang ditawarkan oleh industri perbankan dapat memberikan dampak positif kepada implementasi green banking sehingga dapat meningkatkan perilaku aktivitas perbankan yang ramah lingkungan. Hal ini dapat meningkatkan aktivitas industri perbankan untuk melaksanakan green banking karena jika Green Competitive Strategies berjalan dengan baik maka green banking dapat terlaksana dengan lancar (Naser, 2016).

\section{Kesimpulan}

Green Investment dan Green Competitive Strategies, berdampak pada pelaksanaan Green Banking di Kota Surakarta. Variabel yang paling besar berpengaruh adalah Green Competitive Strategies. Bank hendaknya memprioritaskan gaya hidup hijau menjadikan masyarakat Indonesia yang harus peduli untuk 
menjaga kelangsungan hidup dan menjaga kelestarian lingkungan. Bank hendaknya terus mengembangkan strategi-strategi yang mampu memberikan motivasi dalam melaksanakan green banking.

\section{Daftar Pustaka}

Benedikter, R. (2011). Answers to the Economic Crisis: Social Banking and Social Finance, Spice Digest New York: Springer.

Chen, Y. (2010). The Drivers of Green Brand Equity: Green Brand Image, Green Satisfaction and Green Trust. Journal of Business Ethics. Vol. 93, No. 2, pp. 307-319.

Deka, G. (2015). Green Banking Practices: A Study On Environmental Strategies Of Banks With Special Reference To State Bank Of India. Indian Journal of Commerce E Management Studies. Volume VI Issue 3: 11-19

Goyal, K.A. \& Joshi, V. (2011). A Study of Social and Ethical Issues in Banking Industry. International Journal of Economics and Research. Vol. 2. No. 5. pp. 49-57.

Heim, G. \& Zenklusen, O. (2005). Sustainable Finance: Strategy Options for Development Financing Institutions' Eco: Fact, Stampfenbachstrass.

IFC [International Finance Corporation]. 2016. How Banks Can Seize Opportunities In Climate And Green Investment. IFC Press.

Jones, B. (2001). Emerging Technologies - Accessibility and Web Design Why Does It Matter?. Language Learning and Technology Vol.5. pp. 11-19.

Jun, M. \& Cai S. (2001). The Key Determinants of Internet Banking Service Quality: A Content Analysis. International Journal of Bank Marketing Vol. 19, No.7, 276-291.

Brockmann, K.L. (2017). Green Finance - Green Banking. KfW Research Focus on Economics. No. 189: 1-7. Azad, N. (2016). Identifying and Ranking the Affecting Factors of the Green Banking on Banks Competitive Market (State-Owned Banks and Private Population of Tehran). The Caspian Sea Journal. Volume 10, Issue 1, Supplement 1. pp. 03-08.

Lalon, R.M. (2015). Green banking: Going green. International Journal of Economics, Finance and Management Sciences. Vol. 3(1):34-42.

Meena, R. 2013. Green Banking: As Initiative for Sustainable Development. Global Journal of Management and Business Studies. Volume 3, Number 10. pp. 1181-1186

Garg, S. (2015). Green Banking: An Overview. Global Journal of Advanced Research. Vol-2, Issue-8 pp. 12911296.

Bihari, S.C. (2015). Green Banking In India. Journal of Economisc and International Finance. Volume 7: 117.

Choudhury, T.T. (2013). Influence of Stakeholders in Developing Green Banking Products in Bangladesh. Research Journal of Finance and Accounting. Vol.4, No.7, 2013: 67-77.

Tu, T.T.T. (2017). Factors Affecting Green Banking Practices: Exploratory Factor Analysis On Vietnamese Banks. Journal of Economic Development. Volume 24(2) 14-30. 